\title{
Genetic improvement of sow longevity and its economic impact on commercial pork production
}

\author{
B.E. Mote ${ }^{1}$, T.V. Serenius ${ }^{2}$, C. Supakorn ${ }^{3}, \&$ K.J. Stalder ${ }^{3 \#}$ \\ ${ }^{1}$ Department of Animal Science, University of Nebraska, Lincoln 68503, U.S.A. \\ ${ }^{2}$ Figen Oy, Pietarsaari, Finland, EU \\ ${ }^{3}$ Department of Animal Science, lowa State University, Ames 50011, U.S.A.
}

(Presented at the Ensminger Symposium 22-23 May 2019, Pretoria, South Africa; First published online 11 January 11, 2020)

Copyright resides with the authors in terms of the Creative Commons Attribution 4.0 South African Licence.
See: http://creativecommons.org/licenses/by/4.0/za
Condition of use: The user may copy, distribute, transmit and adapt the work, but must recognise the authors and the South African
Journal of Animal Science.

\begin{abstract}
Sow longevity (sow productive lifetime) plays an important role in economically efficient piglet production. Direct selection for sow longevity is not commonly practiced in any pig-breeding program. In recent years, an increased number of peer reviewed articles addressing the economic impact, genetic parameter estimates, and genomic information (including markers and single nucleotide polymorphisms for sow longevity) have been published in the scientific literature. The studies in the literature indicate that sow longevity is a complex trait having economic value and is an animal well-being concern for commercial pork producers. Studies have concluded that sufficient genetic variation exists so that selection to improve sow longevity should be effective. Unlike the dairy industry, the primary parent animal used in the swine industry is a crossbred female, typically $F_{1}$ (Landrace $X$ Large White or Yorkshire). Sow longevity has shown to be genetically related with prolificacy and leg conformation traits. Sow longevity seems to be the ideal trait to utilize genomic selection when attempting to improve the trait. The genetic correlation between purebred and crossbred sow longevity is low. Since the crossbred sow is the breeding objective, phenotypic data from the crossbred females should ideally be used when estimating the breeding values for sow longevity that are used in the indexes to evaluate nucleus animals. Genomic selection is best suited for sex-limited traits, traits expressed later in life, and many animals do not reach some defined end-point parity, sow longevity seems ideally suited to be evaluated using the latest genome enabled selection technology.
\end{abstract}

Keywords: heritability, leg conformation, selection, sow productive lifetime

\#Corresponding Author: stalder@iastate.edu

\section{Introduction}

Sow longevity is an important component in commercial piglet production for several reasons. First, sow longevity or length of productive life is directly related to the number of piglets produced during a sow's productive lifetime. Second, the risk of introducing a disease not already present in the herd increases as the gilt number and replacement frequency increases. Third, it is not acceptable from an animal welfare perspective to base pork meat production from sows that are not capable of handling the physiological stress associated with commercial pork production over numerous parities. Recent commercial production summaries indicate that the average parity at culling is approximately 3.5 to 4.0 parities. Work by Stalder et al. $(2000,2003)$ indicates that sows do not 'pay for themselves' until the third or fourth parity depending on whether the operation sells market hogs (U.S. average weight of market hog is approximately $127 \mathrm{~kg}$ ) or weaned pigs (U.S. average weight of weaned pigs is 6 to $7 \mathrm{~kg}$ ). Thus, commercial producer management practices and the genetic supplier's breeding program should focus on improving sow longevity (sow productive lifetime) in order to improve the producer's economic production efficiency and profitability, as well as the sow's well-being.

Breeding value estimation is the basis for efficient selection when breeders improve all economically important traits in most domesticated food producing animal species. This includes swine where the important swine production traits are commonly included in a selection index to simultaneously improve the traits in the lines undergoing the selection process. Many breeders and/or breeding stock companies have included sow longevity/sow productive lifetime in the indexes to improve maternal lines. Based on the 
scientific literature, there is no consensus among researchers when it comes to choosing the single best method to estimate breeding values for sow longevity. Two methods that are distinctly different have generally been identified when estimating breeding values for sow longevity / sow productive lifetime. The first method is survival analysis and the second method is a modified linear model analysis. For any selection program to be successful, genetic parameter estimates (heritability and genetic correlation estimates) are needed for the population being evaluated. Survival analysis and various linear model methods are efficient when estimating the heritability for the various measures of longevity. Ideally, a relatively high genetic association between sow longevity and other economically important traits is included in a typical pig breeding program, which demonstrates the importance of multiple-trait evaluation. Because genetic parameter estimates have been published for sow longevity and other economically important traits, including their relationship with each other, it is possible to estimate changes in sow longevity when breeders focus their selection on other economically important traits, such as carcass quantity (percentage of lean meat and backfat thickness). Thus, the objective of current paper is to review the current knowledge concerning genetic parameter estimates of genetic markers and single nucleotide polymorphisms and genomic selection used to improve sow longevity/sow productive lifetime. Furthermore, the paper will review the association of sow longevity with feet and leg soundness traits and reproductive performance traits. Finally, this paper provides a brief review of the economic importance, new technologies impacting, and other factors impacting sow longevity/sow productive lifetime.

\section{Methods to Estimate Sow Longevity Breeding Values}

Survival analyses are considered theoretically superior for conducting a longevity analysis (e.g., Caraviello et al., 2004; Serenius, 2004). This approach properly accounts for censored observations, nonnormal distribution, and model time-dependent effects. Historically, only single-trait analysis was possible when using the Survival Kit. More recently, Maia et al. (2014) have described the development of multivariate survival mixed models that can be used when evaluating longevity traits that allow for data censoring and many of the advantages survival analyses brings to these types of analyses. The advantage for the linear model analysis is that multiple-trait models are possible. These models are based either on analysis of length of productive life (Van Raden \& Klaaskate, 1993; Guo et al., 2001; Caraviello et al., 2004; Serenius \& Stalder, 2004) or a trait that is referred to as 'stayability'. Stayability is recorded as a binary variable based on whether an animal has reached some fixed time period; for example, a sow reaching some fixed parity (Tholen et al., 1996a,b; Boettcher et al., 1999; López-Serrano et al., 2000). Veerkamp et al. (2001) and Meuwissen et al. (2002) extended stayability models to incorporate repeated records, in which the animal is determined to be in production or removed from the herd (culled or died) at any given time. The repeated records generated can then be analysed using repeatability or random regression models. The results from the linear model analyses may be easier to interpret because the breeding values generated as the output from these models are in the units of original variable when compared to the hazard ratios generated from the survival analyses. Additionally, the binary stayability traits benefit from the ability to be analysed with a threshold model (Engblom et al., 2016). Sires ranked very similarly, regardless of whether censoring was accounted for, if all the available data were included in the threshold analysis (Engblom et al., 2016)

Serenius and Stalder (2004) compared sow longevity breeding values from survival analysis and 7trait linear model analysis when only including animals with complete records. When only animals with complete records were included, they observed relatively low correlations $(0.40$ to 0.72$)$ between the breeding values using the survival and linear model methods. The low correlation between the two methods does not identify which method is the best when choosing either the survival method or the linear model method to predict longevity breeding values for a population. Further, the genetic correlations have been very small to zero when examining crossbred and purebred reproductive traits (Abell et al., 2016). This suggests that improving the breeding objective, the crossbred female, requires that breeders obtain data from crossbred females that would be used in the calculation of the estimated breeding values for nucleus animals. However, more work in this area is needed which examines whether using only the records from purebred animals producing at the multiplier level might be more useful when comparing with records obtained from $F_{1}$ females in production at the commercial level of a production system.

\section{Genetic Variation}

Throughout the scientific literature, heritability estimates indicate that selection to improve sow longevity should be effective (Table 1). Reviewing the literature, the size of heritability estimates varies and seems to be based on the sow longevity trait definition used and the population evaluated. Heritability estimates for sow longevity based on survival analysis have ranged from 0.11 to 0.31 (Yazdi et al., 2000a,b; Serenius \& Stalder, 2004) and estimates based on a linear model of stayability have ranged from 0.02 
Table 1 Heritability estimates and genetic correlations with sow longevity measured as stayability or length of productive life and other important swine traits

\begin{tabular}{|c|c|c|c|c|c|c|c|}
\hline \multirow{2}{*}{ Trait } & \multicolumn{3}{|c|}{ Heritability } & \multicolumn{3}{|c|}{ Genetic correlation } & \multirow{2}{*}{ Study } \\
\hline & Average & Minimum & Maximum & Average & Minimum & Maximum & \\
\hline Stayability & 0.08 & 0.02 & 0.10 & - & - & - & $\begin{array}{l}\text { Tholen et al., 1996a } \\
\text { Tholen et al., 1996b } \\
\text { Lo' pez-Serrano et al., } 2000 \\
\text { Le et al., } 2015\end{array}$ \\
\hline Length of productive life, Survival analysis & 0.17 & 0.05 & 0.31 & - & - & - & $\begin{array}{l}\text { Yazdi et al., 2000a } \\
\text { Yazdi et al., 2000b } \\
\text { Serenius and Stalder, } 2004\end{array}$ \\
\hline Length of productive life, linear model & 0.13 & 0.05 & 0.34 & - & - & - & $\begin{array}{l}\text { Guo et al., } 2001 \\
\text { Serenius and Stalder, } 2004 \\
\text { Serenius et al., } 2008 \\
\text { Sevón-Aimonen \& Ulmari, } 2013 \\
\text { Le et al., } 2015 \\
\text { Engblom et al., } 2016\end{array}$ \\
\hline Leg conformation & 0.11 & 0.06 & 0.15 & 0.22 & 0.00 & 0.39 & $\begin{array}{l}\text { Lo' pez-Serrano et al., } 2000 \\
\text { Serenius and Stalder, } 2004 \\
\text { Aasmundstad et al., } 2014 \\
\text { Le et al., } 2015\end{array}$ \\
\hline Age at first farrowing & 0.10 & 0.04 & 0.16 & 0.36 & & & $\begin{array}{l}\text { Serenius and Stalder, } 2004 \\
\text { Engblom et al., } 2016\end{array}$ \\
\hline Farrowing interval & 0.04 & 0.00 & 0.10 & -0.40 & -0.54 & -0.24 & $\begin{array}{l}\text { Tholen et al., 1996a } \\
\text { Tholen et al., 1996b }\end{array}$ \\
\hline Wean-to-estrus interval & 0.07 & 0.04 & 0.10 & -0.33 & -0.45 & -0.22 & $\begin{array}{l}\text { Tholen et al., 1996a } \\
\text { Tholen et al.,1996b } \\
\text { Serenius et al., } 2008 \\
\end{array}$ \\
\hline Litter size & 0.08 & 0.03 & 0.16 & 0.27 & -0.25 & 0.45 & $\begin{array}{l}\text { Tholen et al.,1996b } \\
\text { Serenius and Stalder, } 2004 \\
\text { Le et al., } 2015\end{array}$ \\
\hline Average daily gain & 0.37 & 0.29 & 0.41 & -0.15 & -0.32 & -0.06 & $\begin{array}{l}\text { Tholen et al., 1996a } \\
\text { Lo'pez-Serrano et al., } 2000 \\
\text { Serenius and Stalder, } 2004\end{array}$ \\
\hline Backfat thickness & 0.37 & 0.30 & 0.68 & 0.14 & -0.03 & 0.36 & $\begin{array}{l}\text { Tholen et al., 1996a } \\
\text { Lo'pez-Serrano et al., } 2000 \\
\text { Serenius and Stalder, } 2004 \\
\text { Nikkilä et al., } 2013\end{array}$ \\
\hline
\end{tabular}


to 0.11 (Tholen et al., 1996a,b; López-Serrano et al., 2000; Le et al., 2015). Serenius and Stalder (2004) analysed length of productive life using data from the Finnish Landrace and Large White breeds using both a survival analysis and a linear model. They reported that heritability estimates obtained using the linear model were clearly lower than the estimates obtained implementing a survival analysis (linear model $\mathrm{h}^{2}$ estimates range 0.05 to 0.10 vs survival analyses $h^{2}$ estimates range 0.16 to 0.19 ).

The effects of different censoring rates on the heritability estimates for lifetime prolificacy and length of productive life by using censored records in linear model analysis have been evaluated (Guo et al., 2001). As one might expect, increased censoring rate seemed to result in reduced heritability estimates. For example, when $35 \%$ of the records were censored, the heritability estimates for lifetime prolificacy and length of productive life were 0.16 and 0.15 , and when the percentage of censored records dropped to $15.5 \%$ (less than half of the previous censoring), the heritabilities increased to 0.25 and 0.22 for the same traits. The same study reported that the lifetime prolificacy trait was slightly less heritable $\left(\mathrm{h}^{2}\right.$ ranged from 0.17 to 0.25$)$ when compared to the length of productive life trait $\left(\mathrm{h}^{2}\right.$ ranged from 0.16 to 0.34$)$. The results obtained from Gou et al. (2001) are in agreement with those later reported by Serenius and Stalder (2004). Serenius and Stalder (2004) reported that the genetic correlation between length of productive life and lifetime prolificacy is very high (>0.95). Hence, if breeders place selection emphasis on one trait, genetic gain will occur in the other trait.

Crossbred sows (Landrace $X$ Large White or Yorkshire $F_{1}$ or similar parent female) make up the breeding herd female population in the majority of commercial operations. Swine geneticists should keep in mind that the goal of breeding for sow longevity is to genetically improve the length of productive life for both purebred (or pure line) females at the multiplier level and the $F_{1}$ crossbred sows that are producing in the breeding herd of a large number of commercial production systems. Ultimately, the pork producer's objective is to reduce their cost of production associated; this includes the cost that each individual sow contributes to the overall cost of a $\mathrm{kg}$ of pork produced by a particular production system. This goal raises questions concerning non-additive genetic variation, ideal or optimum crossbred model, and the role genomic selection should contribute to nucleus, multiplication, and commercial levels of the breeding pyramid when estimating breeding values for sow longevity and associated traits. Currently, literature estimates for non-additive effects on sow longevity are limited. Estimates for dominance variation relative to total genetic variation for average daily gain have been moderate, while they have been near zero when examining the impact of dominance variation on carcass traits (Lutaaya et al., 2001). This research indicates that non-additive genetic effects should be accounted for when estimating breeding values for some economically important pork production traits. Dominance may play a significant role in sow longevity inheritance because it is a 'fitness trait' (Falconer \& Mackay, 1996). Relatively high dominance variance estimates (0.19 to 0.52) have been reported for length of productive life and lifetime production in dairy cattle (Fuerst \& Sölkner, 1994).

\section{Early indicators for Sow Longevity}

Because sow longevity information can be recorded only after the sow has been culled or has died (i.e. the sow has completed its production record), sow longevity selection decisions must be carried out using information from relatives (through pedigree) and genomic information. Thus, traits recorded earlier in life that have relatively high genetic correlations with sow longevity/sow productive lifetime could improve the breeding value accuracy. Traits that have been used as early indicators for outstanding sow longevity / sow productive lifetime include prolificacy and feet and leg conformation traits (Serenius et al., 2004; Le et al., 2015)

\section{Prolificacy Traits}

Stalder et al. (2004), in a review of the scientific literature, noted that reproductive failure is the predominant reason young sows are culled from commercial breeding herds. A moderate negative genetic correlation (0.40 and -0.43 ) was reported between farrowing interval and length of productive life from a study involving Finnish Landrace and Large White populations (Serenius \& Stalder, 2004). The genetic correlation between farrowing interval and stayability (a measure of sow longevity) has been reported to be moderate to relatively large and negative (ranging from -0.24 and -0.54) (Tholen et al., 1996b) Low feed intake and high backfat loss during lactation has been reported to be detrimental to the sow's longevity (Serenius et al., 2005).

There seems to be an association between litter size and sow longevity because of the impact that litter size plays in a producer's sow culling decisions. When evaluating field data, litter size is associated with sow longevity. However, Serenius et al. (2005) found that litter size and sow longevity were only statistically significantly associated with length of productive life only in 2 out of 6 lines evaluated. Culling of sows due to poor production was not allowed until the fourth parity. Examining the differences among the studies shown in Table 1, one can raise a question whether the associations between litter size and sow longevity reported in the studies based on field data are a result of autocorrelation (i.e., by the fact that farmers are not retaining 
or keeping sows that produce small litters).

\section{Leg Conformation}

After reproductive failure, lameness / feet and leg problems / leg weakness is the next most common reason for sows being culled from the breeding herd (Stalder et al., 2004). The genetic correlations between sow longevity and leg conformation traits are variable depending on the population that is evaluated. A moderate (0.32) genetic correlation between overall leg action and length of productive life was reported in a study of a Finnish Landrace population. The genetic correlation between the same traits was only 0.17 when the Finnish Large White population was evaluated (Serenius \& Stalder, 2004; Le et al., 2015). The genetic correlation between leg score and stayability was moderate (ranging from 0.19 and 0.36 ) when evaluating a German Landrace population. However, the genetic correlations between the same traits was close to zero when evaluating a German Large White population (López-Serrano et al., 2000). The correlations between osteochondrosis and length of productive life were similar although low (0.08 to 0.12) in Swedish Landrace and Yorkshire populations (Yazdi et al., 2000a).

The heritability for leg conformation traits reported in the scientific literature have ranged from very low (0.01) to moderate or even relatively large (approximately 0.40) (Bereskin, 1979; Webb et al., 1983; Jörgensen and Vestergaard, 1990; Huang et al., 1995; Stern et al., 1995; López-Serrano et al., 2000; Serenius et al., 2001; Le et al., 2015). The large variation in the heritability estimates is likely the result of the population evaluated, and the model used to analyse the data. In addition to heritability estimates, the associations between the different feet and leg conformation measures and sow longevity and their associations with each other determine which traits should be included in an index for overall leg index. Ultimately, the economic weights for leg conformation traits are driven by their association with sow longevity.

Jörgensen (1996) reported that buck-kneed front legs, up-right or straight pasterns on the rear legs, and swaying hindquarters were significantly and unfavourably associated with sow longevity. Moreover, he reported that weak pasterns on the front are favourably associated with sow longevity. Grindflek and Sehested (1996) reported similar results where unfavourable associations between upright rear pasterns and favourable associations between soft front pasterns with sow longevity were reported. Additionally, several studies have reported that the buck-kneed front leg trait is genetically correlated with overall leg action (indicates the pig's ability to move freely without any leg pain) (Webb et al., 1983; Jörgensen and Vestergaard, 1990; Serenius et al., 2001). The rear leg anatomy of ungulates has been described as less optimal for weight bearing, as this is the primary role of the front legs (Greenough et al., 1981; Nickel et al., 1986). This would seem to suggest that rear leg structure is more important for obtaining good sow longevity. Current selection for increased growth rate and greater lean percentage resulting in larger hams and loins combined with effective selection for increased number born alive places strain on the conformation of maternal line females especially when they are in late gestation. This makes feet and leg structural soundness more important in breeding females. Aasmundstad et al. (2014) suggests that as long as positive genetic correlations between the conformation traits exists, including several of these traits in a selection program should function as repeated measures and possibly strengthen the overall correlation between overall leg action and longevity.

\section{Sow Longevity and Meat Production Trait Associations}

Much of the phenotypic improvement for terminal production traits (e.g., ADG, G:F, carcass lean percentage) has been obtained during last 30 years (Boyd, 1999; FABA, 2002) has resulted from genetic improvement. During this same period, sow longevity has not improved. This seems to question whether unfavourable genetic associations between sow longevity and the terminal traits exist. Reports in the scientific literature do not consistently support this notion, while another study reported that the genetic correlation estimates between stayability and backfat thickness ranged from -0.03 to 0.36 , and similarly from 0.02 to -0.13 for ADG (Tholen, 1996b). An unfavourable genetic correlation (0.22) between length of productive life and backfat thickness was reported in a study involving a Finnish Large White population (Serenius \& Stalder, 2004). That study also reported that the same genetic correlation was close to zero when evaluating the Finnish Landrace population. Furthermore, the Serenius and Stalder (2004) study did not support that ADG is significantly correlated with either length of productive life or lifetime prolificacy. Stalder et al. (2005) indicated that the relationship between gilt backfat thickness and sow longevity might be nonlinear. They grouped the gilts based on the standard deviation of backfat thickness, loin muscle area, and days from birth to $113 \mathrm{~kg}$ of live weight, and found that gilt's from lowest backfat category clearly had a lower lifetime prolificacy, whereas the gilts from the highest backfat group had a greater length of productive life compared with sows in other groups. More research is needed to determine whether a threshold might exist for the ideal gilt's backfat thickness to maximize or optimize length of productive life. Even though a general 
unfavourable association between carcass traits and sow longevity has been reported from the scientific literature, it should be noted that the relationships are not extremely large, indicating that simultaneous selection to improve both traits is likely possible.

\section{Breeding source}

Choice of breeding stock source could also impact a producer's ability to retain sows in the breeding herd for longer periods of time. The National Pork Board's Maternal Line Project demonstrated that traits contributing to longevity and attrition are heritable (Johnson, 2000). This report identified line differences for a sow's ability to complete four litters, live pigs produced per sow lifetime, and average sow lifetime. Goodwin (2002) extended the analysis of the same maternal line study and found similar differences through the sixth parity. Because genetic line differences exist and the heritability for longevity traits is greater than zero, pork producers can identify maternal lines that have improved sow longevity/sow productive lifetime. At the same time, genetic suppliers can continue to improve this trait through selection. Producers should keep in mind that they would be responsible for a portion of the improvement (selecting for feet and leg soundness, providing longevity information from crossbred sows to their genetic supplier to be used in purebred genomic evaluation) in sow longevity if internal gilt multiplication systems are employed. In that case, genetic improvement of sow longevity must occur through semen (most often) or boars (less often) from their genetic supplier and through selecting replacement females with superior traits impacting sow longevity/sow productive lifetime.

A key point that makes the swine industry different than the dairy industry for example is the use of crossbred (typically, $F_{1}$ Landrace $X$ Large White or Yorkshire) females at the parent or commercial production level. In the dairy industry, the Holstein breed was superior even to the crossbred cow, such that purebred cows are commonly used in the commercial dairy industry. Many studies investigating the survival or longevity for the purebred cows have a direct impact on the commercial dairy industry. A relatively recent study suggests that the genetic correlation between purebred and crossbred reproductive traits in sows were close to zero (Abell et al., 2016). Selection for improved longevity at the nucleus level may not result in improved longevity and lifetime performance at the crossbred level. Using crossbred records in the selection program to improve the associated pure lines is likely the best way to improve crossbred sow longevity. However, more work needs to be done to compare longevity from only the multiplication level of the production system with longevity obtained from the $F_{1}$ females used in commercial production. Contrary to nucleus sows, sows at the multiplication level are not culled as a result for the need for rapid genetic progress (reducing generation interval). Thus, the genetic correlation for longevity traits may be greater if only information from purebred animals from multiplication are used to obtain genetic correlations with the $F_{1}$ animals in the same population.

\section{Other factors impacting sow longevity}

In addition to the direct genetic effects associated with sow longevity and the genetic affects impacting sow longevity through associated traits like feet and leg structure, there are various other factors that can have a significant influence on sow longevity. Serenius and Stalder (2007) reported that length of productive life was influenced by age at first farrowing and litter size at first farrowing. They reported that the younger age at first farrowing and the larger the litter size at first farrowing, the longer the sows tended to remain in the breeding herd. Although only trending towards significance, sows born in litters first, second, and sixth parities had slightly greater risk of being culled when compared to sow from other parities. Similarly, Knauer et al. (2010) identified factors impacting a sow's stayability to the fourth parity included farm, entry age, age at puberty, age at first farrowing and lactation feed intake. Age at puberty, age at first farrowing, and lactation feed intake had the greatest effect on stayability to the $4^{\text {th }}$ parity in this study.

\section{New Genetic Approaches}

Genetic approaches developed in recent years seem ideally suited to improve a trait like sow longevity/sow productive lifetime. Sequencing the pig's genome will allow faster improvement of economically important traits than was possible prior to the molecular age (Groenen et al., 2016). A review of the advance made in recent years has been nicely summarized in a paper by Rothschild (2019) made at the South African Ensminger Swine Seminar. To summarize, early studies identified genetic markers for productive lifetime (Mote et al., 2009) and associated traits like lifetime reproductive traits (Onteru et al., 2011) and leg weakness (Fan et al., 2009). The molecular genetic developments provide breeders with ability to investigate individual gene effects on longevity and most importantly the interaction of these genes with genes influencing other economically important traits in swine. Genes have been identified that have significant effects on longevity (Mote et al., 2006). However, the size and direction of genotypic effects vary among lines and herds. Furthermore, two of these genes have additive effects on other production traits, 
suggesting that if selection for the beneficial form of the gene is made, then the producer can benefit from improvement in multiple traits.

Advancements in molecular technology now allow breeders to identify single nucleotide polymorphisms for the same economically important traits for swine populations (Tart et al., 2013). Progress in both the molecular technology and the quantitative areas (Meuwissen et al., 2001) has been made in more recent years to better predict the association between purebred and crossbred performance (IbánẽzEscriche et al., 2009) and provide genomic breeding values (Calus, 2010). Advancements in this field have continued at a relatively rapid pace, to the point genomic evaluations of entire breeding populations are now possible. This abundant information can be used to improve the selection of breeding animals to make even more rapid genetic progress than what was ever thought possible even for some of the lowlier heritable traits (Dekkers, 2007).

Regardless of the genetic method being utilized, until the actual gene(s) influencing economically important production traits are identified, testing a genetic marker, QTL, or SNP, a new molecular method must be evaluated on the populations it will be used in to be sure of its effects before it can be used for widespread selection purposes within a population. However, it is clear that molecular tools can be used to improve sow longevity genetically. Breeders have the ability to select the beneficial forms of certain genes to improve the ability of sows to have longer productive herd life, improved sow longevity, or have greater lifetime productivity.

A trait like sow longevity / sow productive lifetime is an ideal trait to utilize genomic selection to help improve the trait more rapidly than could be done by traditional selection because it is a trait that is sex limited (phenotype is measured only on sows), trait is measured at or near the end of the animals life (whether productive lifetime is measured to some predetermined breakeven parity or truly when the sow exits the herd by death or is culled), the trait is not measured on the nucleus animals because the goal is to minimize generation interval (so connecting crossbred information back to the pure-line or purebred parent is necessary). However, it may not make sense for all breeders to utilize this tool due to costs associated with different implementation strategies such as marker panels with varying densities and the identification of animals to be genotyped (Abell et al., 2014). The genotyping strategy will have to be carefully thought out when trying to lower breeder costs and maximize genetic gain when implementing genomic selection in any breeding population.

\section{Economic Importance}

Improving sow longevity can have a substantial economic impact on the farm or the integrated production system (Kroes \& Van Male, 1979). Sehested (1996) reported that improving longevity by one parity had the same impact as improving lean meat percentage by $0.5 \%$. This same study reported that the value of improving longevity tends to decrease with increasing parity of culling and likely has little economic impact once average parity at culling is above five.

Conversely, a study conducted by Parsons et al. (1990) suggested that productivity of a stable swine herd and hence, its economic status was insensitive to parity distribution and its underlying culling strategies, both of which are factors in determining sow longevity. Mote et al. (2009) suggested that improving sow productive lifetime by one-tenth of 1 parity would result in an annual revenue increase of over $\$ 15$ million in the US. Simulation models have been used to examine the effect of culling rate, replacement gilt cost and other factors on the profitability of commercial swine operations. Faust et al. (1992, 1993a) developed simulation models of swine breeding system to evaluated various effects, including culling, on profitability. The simulation models demonstrated that systems with the lowest commercial replacement rates (i.e. herds with better sow longevity) were most profitable and when high replacement rates occurred, replacement gilts were worth no more than 175 percent of market value. Conversely, when replacement rates were low, replacement gilts were worth as much as 450 percent of market value. As one might expect, the results from the simulated findings showed that larger economic benefits occurred when sow maximum parity increased from one to five than from when maximum parity increased from five to ten (Faust et al., 1993b).

It has been reported that piglet breeding costs were reduced by $\$ 1.61$ when sows with high lifetime production values (high lifetime production values would presume better sow longevity), when compared to sows with low lifetime production values (Paterson et al., 1997). These results are supported by a recent study showing the lowest variable produced occurs in $6^{\text {th }}$ parity and variable costs from the $7^{\text {th }}$ to $10^{\text {th }}$ parity never exceed the variable cost occurring in parity 1, 2, or 3 (Gruhot et al., 2017). Dhuyvetter (2000) suggested that the optimal economic time to cull a sow is after her $8^{\text {th }}$ or $9^{\text {th }}$ parity. However, additional economic benefits of keeping a sow past the sixth parity become marginally less. These results are supported by the more recent findings reported by Gruhot et al. (2017) that the optimal parity to cull a sow is after her $6^{\text {th }}$ or $7^{\text {th }}$ parity with the return over variable costs at the $10^{\text {th }}$ parity still greater than the same value at the $3^{\text {rd }}$ parity. 


\section{New Technologies}

Technologies will not only result in continued improvement in both the molecular and quantitative genetic fields but will likely help swine producers and breeders collect improved and new phenotypes to make better selection decisions. One example of this is moving feet and leg evaluation from a subjectively evaluated trait to one that is objectively evaluated using digital imagery technology (Stock et al., 2017). New technologies have the opportunity to change some phenotypes from subjective evaluations to objective evaluations where improved heritability estimates result because the human element is removed from the process (Stock et al., 2018). New phenotypes related to disease susceptibility, resistance, or resilience might be identified using developing audiology or imagery technology. Identifying behavioral traits in the sow herd or any part of the nursery to finishing area, as well as the gilt development area, will become commonplace as hardware and software technology advances. Finally, the animal industry, including the animal breeding field, is benefiting from advances in hardware (computer speed increasing, and camera abilities because of the gaming industry, increased microprocessor and storage space occurring because of needs occurring in other industries) and software improvements (taking advantage of software improvements made for other fields). In other words, rarely do technological advancement occur because the animal industry develops a new tool from scratch. Rather, the animal industry has to continue examining the advancements occurring in other industries and ask the question, how can new development made elsewhere be used to improve the animal breeding area or result in the development of a new phenotype?

\section{Conclusions}

Heritability estimates for sow longevity / sow productive lifetime presented in the literature indicate that sufficient genetic variation is present in most swine populations enabling sow longevity to be improved through selection. Identifying the proper methodology swine breeders should use to improve the trait within their nucleus populations is challenging because of the need to maintain generation interval as low as possible. Survival analysis is generally considered theoretically appropriate in the analysis of this type of data; however, this may present challenges resulting from the fact that the relationship between purebred and crossbred sow longevity is poor. A trait like sow longevity / sow productive lifetime seems ideally suited for genomic selection as it a sex limited trait (trait measured in only females), and is measured at the end of productive life (typically after approximate reach 3 years of age or more), is a lowly heritable trait (as is expected with fitness / reproductive traits) and genetic markers or SNPs have been identified that are associated with the trait in some populations. More research is needed to identify the best methodology for estimating breeding values for sow longevity when incorporating relatives including crossbred data. More research also is needed to determine the magnitude of non-additive genetic variation that affects sow longevity as well as to identify and collect the most appropriate phenotypes.

\section{Acknowledgements}

Support from the Department of Animal Science, College of Agriculture and Life Sciences at lowa State University and the Ensminger International fund is graciously acknowledged. The authors would like to thank former graduate students and academic and industry colleagues that continue to contribute to the sow longevity research and outreach activities of our group that make this work like this possible.

\section{Authors' Contributions}

BEM reviewed and contributed material for the article and made the formal presentation of the material in this manuscript at the Ensminger Pig Symposium held at the Kopanong Conference Center, Johannesburg, South Africa, May 22-23, 2019. TVS contributed material for this paper, CS identified current references, provided material used in this manuscript, and reviewed the manuscript, KJS wrote the majority of the manuscript made revisions suggested by coauthors and served as the corresponding author.

\section{Conflict of Interest Declaration} manuscript.

We certify that there is no conflict of interest with any organization regarding the material discussed in the

\section{References}

Aasmundstad, T., Olsen, D., Sehested, E. \& Vangen, O., 2014. The genetic relationships between conformation assessment of gilts and sow production and longevity. Livest. Sci. 167, 33-40.

Abell, C.E., Dekkers, J.C.M., Rothschild, M.F., Mabry, J.W. \& Stalder, K.J., 2014. Total cost estimation for implementing genome-enable selection in a multi-level swine production system. Gen. Sel. Evol. 46, 32 doi:10.1186/1297-968646-32.

Abell, C.E., Fernando, R.L., Serenius, T.V., Rothschild, M.F., Gray, K.A., \& Stalder, K.J., 2016. Genetic relationship between purebred and crossbred sow longevity. J. Anim. Sci. Biotech. 7, 51. doi:10.1186/s40104-016-0112-x 
Bereskin, B., 1979. Genetic aspects of feet and legs soundness in swine. J. Anim. Sci. 48, 1322-1328.

Boyd, J., 1999. A three-diet strategy for the lifetime feeding of gilts and sows. Pig Reproduction: Problems, Practices and Principles. Compac Associates Publication, Chippenham, UK.

Calus, M.P., 2010. Genomic breeding value prediction: methods and procedures. Anim. 4, 157-164.

Caraviello, D.Z., Weigel, K.A. \& Gianola, D., 2004. Comparison between a Weibull proportional hazard model and a linear model for predicting the genetic merit of US Jersey sires for daughter longevity. J. Dairy Sci. 87, 1469-1476.

Dekkers, J.C.M., 2007. Prediction of response to marker-assisted and genomic selection using selection index theory. J. Anim. Breed. Genet. 128, 3-14.

Dhuyvetter, K.C., 2000. What does attrition cost and what is it worth to reduce? In: Proceedings of the Allen D. Leman Swine Conference, University of Minnesota, Minneapolis, MN, Sept. 16-19, 2000, 27, 110-116.

Engblom, L., Calderón Díaz, J.A., Nikkilä, M., Gray, K., Harms, P., Fix, J., Tsuruta, S., Mabry, J. \& Stalder, K., 2016. Genetic analysis of sow longevity and sow lifetime reproductive traits using censored data. J. Anim. Breed. Genet. 133, 1-7. doi: 10.1111/jbg.12177.

FABA., 2002., Kotiela" injalostuksen tilastokirja (Animal Breeding Sta- tistics). Finn. Anim. Breed. Assoc. (FABA), Vantaa, Finland.

Falconer, D.S. \& Mackay, T.F.C., 1996. Introduction to Quantitative Genetics. 4th ed. Longman, Essex, UK.

Fan, B., Onteru, S.K., Nikkilä, M.T., Stalder, K.J. \& Rothschild, M.F., 2009. Identification of genetic markers associated with fatness and leg weakness traits in the pig. Anim. Genet. 40, 967-970.

Faust, M.A., Tess, M.W. \& Robison, O.W., 1992. A bioeconomic simulation model for a hierarchical swine breeding structure. J. Anim. Sci. 70, 1760-1774.

Faust, M.A., Robison, O.W. \& Tess, M.W., 1993a. Genetic and economic analyses of sow replacement rates in the commercial tier of a hierarchical swine breeding structure. J. Anim. Sci. 71, 1400-1406.

Faust, M.A., Robison, O.W. \& Tess, M.W., 1993b. Integrated systems analysis of sow replacement rates in a hierarchical swine breeding structure. J. Anim. Sci. 71, 2885-2890.

Fuerst, C. \& Sölkner J., 1994. Additive and non-additive genetic variances for milk yield, fertility, and lifetime performance traits of dairy cattle. J. Dairy Sci. 77, 1114-1125.

Goodwin, R.N., 2002. Sow longevity differences. In: Proceedings of the National Swine Improvement Federation, Nashville, TN

Grindflek, E. \& Sehested, E., 1996. Conformation and longevity in Norwegian pigs. Pages 77-83 in Proceedings of the Nordiska Jordbruksforskares Forening Seminar 265-Longevity of Sows. Research Centre Foulum, Denmark.

Greenough, P., MacCallum, F. \& Weaver, A., 1981. Lameness in cattle: second ed. Wright-Scientechnica, Bristol. Pp. 151-158.

Groenen, M.A.M., 2016. A decade of pig genome sequencing: a window on pig domestication and evolution. Genet. Sel. Evol. 48, 23. Doi:10.1186/s12711-016-0204-2.

Gruhot, T.R., Calderón Díaz, J.A., Baas, T.J., Dhuyvetter, K.C., Schulz, L.L. \& Stalder, K.J., 2017. An economic analysis of sow retention in a U.S. breed-to-wean system. J. Swine Health Prod. 25, 238-24.

Guo, S.-F., Gianola, D., Rekaya, R. \& Short, T., 2001. Bayesian analysis of lifetime performance and prolificacy in Landrace sows using linear mixed model with censoring. Livest. Prod. Sci. 72, 243-252.

Huang, S.Y., Tsou, H.L., Kan, M.T., Lin, W.K. \& Chi, C.S., 1995. Genetic study on leg weakness and its relationship with economic traits in central tested boars in subtropical area. Livest. Prod. Sci. 44, 53-59.

Ibánẽz-Escriche, N., Fernando, R. L., Toosi, A. \& Dekkers, J.C.M., 2009. Genomic selection of purebreds for crossbred performance. Genet. Sel. Evol. 41, 12 doi.10.1186/1297-9686

Johnson, R., 2000. Role of genetics in gilt attrition. In: Proceedings of the Allen D. Leman Swine Conference 28, 105109.

Jörgensen, B., 1996. The influence of leg weakness in gilts on their longevity as sows, assessed by survival analysis. Pages 95-99 in Proceedings of the Nordiska Jordbruksforskares Forening Seminar 265-Longevity of Sows. Research Centre Foulum, Denmark.

Jörgensen, B. \& Vestergaard, T., 1990. Genetics of leg weakness in boars at the Danish pig breeding stations. Acta Agric. Scand. 40, 59-69.

Knauer, M., Stalder, K.J., Serenius, T., Baas, T.J., Berger, T.J., Karriker, L., Goodwin, R.N., Johnson, R.K., Mabry, J.W., Miller, R.K., Robison, O.W. \& Tokach, M.D., 2010. Factors associated with sow stayability in 6 genotypes. J. Anim. Sci. 88, 3486-3492.

Kroes, Y. \& Van Male, J.P., 1979. Reproductive lifetime of sows in relation to economy of production. Livest. Prod. Sci. 6 , $179-183$

Le, T.H., Norberg, E., Nielsen, B., Madsen, P., Nilsson, K. \& Lundeheim, N., 2015. Genetic correlation between leg conformation in young pigs, sow reproduction and longevity in Danish pig populations. Acta Agric. Scand. Sect. A 65, 132-138. doi: 10.1080/09064702.2016.1153709.

López-Serrano, M., Reinsch, N., Looft, H. \& Kalm, E., 2000. Genetic correlations of growth, backfat thickness and exterior with stayability in Large White and Landrace sows. Livest. Prod. Sci. 64, 121-131.

Lutaaya, E., Misztal, I., Mabry, J.W., Short, T., Timm, H.H. \& Holzbauer, R., 2001. Genetic parameter estimates from joint evaluation of purebreds and crossbreds in swine using the crossbred model. J. Anim. Sci. 79, 3002-3007.

Meuwissen, T., Hayes, B. \& Goddard, M., 2001. Prediction of total genetic value using genome-wide dense marker maps. Genet. 157, 1819-1829.

Meuwissen, T.H.E., Veerkanmp, R.F., Engel, B. \& Brotherstone, S., 2002. Single and multitrait estimates of breeding values for survival using sire and animal models. Anim. Sci. 75, 15-24. 
Maia, R.P., Madsen, P. \& Labouriau, R., 2014. Multivariate survival mixed models for genetic analysis of longevity traits. J. Appl. Stat. 41, 1286-1306. dod:10.1080/02664763.2013.868416.

Mote, B.E., Serenius, T, Stalder, K.J. \& Rothschild, M.F., 2006. The holy grail for pigs: Candidate genes affecting sow productive life. Proc. 8th World Cong. Genet. Appl. Livest. Prod. 20-22, August 13-18, Belo Horizonte, Minas Gerais, Brazil.

Mote, B.E., Koehler, K.J., Mabry, J.W., Stalder, K.J. \& Rothschild, M.F., 2009. Identification of genetic markers for productive lifetime in commercial sows. J. Anim. Sci. 87, 2187-2195

Nickel, E., Schummer, A., \& Seiferle, E., 1986. The anatomy of the domestic animals, Vol.1 The locomotor system of the domestic mammals. Verlag Paul Parey, Berlin - Hamburg, Germany.

Nikkilä, M.T., Stalder, K.J., Mote, B.E., Rothschild, M.F., Gunsett, F.C., Johnson, A.K., Karriker, L.A., Boggess, M.V. \& Serenius, T.V. 2013. Genetic associations for gilt growth, compositional and structural soundness traits with sow longevity and lifetime reproductive performance. J. Anim. Sci. 91, 1570-1579.

Onteru, S.K., Fan, B., Nikkilä, M.T., Garrick, D.J., Stalder, K.J. \& Rothschild, M.F., 2011. Whole-genome association analyses for lifetime reproductive traits in the pig J. Anim. Sci. 89, 988-995.

Parsons, T.D., Johnstone, C. \& Dial, G.D., 1990. On the economic significance of parity distribution in swine herds. In: Proc. Intern. Pig Vet. Soc. 11, 380.

Paterson, R., Mullan, B., Pointon, A. \& Cargill, C., 1997. Investigations of the effect of sow wastage on economic efficiency. Available at: http://www.sardi.sa.gov.au/pages/livestock/pigs/pub/news/jul 97/wastage.htm Accessed: 8, February, 2019.

Sehested, E., 1996. Economy of sow longevity. In: Proceedings of the Nordiska Jordbruksforskares Forening Seminar 265-Longevity of Sows. Ed. V. Danielsen, Denmark: Research Centre Foulum, pp. 101-108.

Serenius, T., Sevón-Aimonen, M.-L. \& Mäntysaari, E.A., 2001. The genetics of leg weakness in Finnish Large White and Landrace populations. Livest. Prod. Sci. 69, 101-111.

Serenius, T., 2004. Genetics of sow efficiency in the Finnish Landrace and Large White populations. Ph.D. Dissertation, University of Helsinki, Finland. Agrifood Res. Rep. 55.

Serenius, T. \& Stalder, K.J., 2004. Genetics of length of productive life and lifetime prolificacy in the Finnish Landrace and Large White pig populations. J. Anim. Sci. 82, 3111-3117.

Serenius, T. \& Stalder, K.J., 2006. Length of productive life of crossbred sows is affected by farm management, leg conformation, sow's own prolificacy, sow's origin parity and genetics. Anim. 1, 745-750. doi:10.1017/S17517310769185X.

Serenius, T. \& Stalder, K.J., 2007. Longevity is impacted by farm management, leg conformation, sow's own prolificacy, and sow's origin parity and genetics. Anim. 1, 745-750.

Serenius, T., Stalder, K.J., Baas, T.J., Mabry, J.W. \& Goodwin, R.N., 2005. A comparison of six maternal genetic lines for sow longevity. J. Anim. Sci. 83 (Suppl. 2):53. (Abstr.)

Serenius, T., Stalder, K. \& Fernando, R. 2008. Genetic associations of sow longevity with age at first farrowing, number of piglets weaned and wean to insemination interval in the Finnish Landrace swine population. J. Anim. Sci. 86, 3324-3329.

Sevón-Aimonen, M.-L. \& Ulmari. 2013. Heritability of sow longevity and lifetime prolificacy in Finnish Yorkshire and Landrace pigs. Agric. Food Sci. 22, 325-330.

Stalder, K.J., Knauer, M., Baas, T.J., Rothschild, M.F. \& Mabry, J.W., 2004. Sow longevity. Pig News Inf. 25, 53-74.

Stalder, K.J., Lacy, R.C., Cross, T.L., Conatser, G.E. \& Darroch, C.S., 2000. Net present value analysis of sow longevity and the economic sensitivity of net present value to changes in production, market price, feed cost, and replacement gilt costs in a farrow-to-finish operation. Prof. Anim. Sci. 16, 33-40.

Stalder, K.J., Lacy, R.C., Cross, T.L. \& Conatser, G.E., 2003. Financial impact of average parity of culled females in a breed-to-wean swine operation using replacement gilt net present value analysis. Swine Health Prod. 11, 69-74.

Stalder, K.J., Saxton, A.M., Conatser, G.E. \& Serenius, T.V., 2005. Effect of growth and compositional traits on first parity and lifetime reproductive. Livest. Prod. Sci. 97, 151-159.

Stern, S., Lundeheim, N., Johansson, K. \& Andersson, K., 1995. Osteochondrosis and leg weakness in pigs selected for lean tissue growth rate. Livest. Prod. Sci. 44, 45-52.

Stock, J.D., Calderón Díaz, J.A., Abell, C.E., Baas, T.J., Rothschild, M.F., Mote, B.E. \& Stalder, K.J., 2017. Development of an objective feet and leg conformation evaluation method using digital imagery in swine. J. Anim. Sci. Livest. Prod. 1, 2.

Stock, J.D., Calderón Díaz, J.A., Rothschild, M.F., Mote, B.E. \& Stalder, K.J., 2018. Objective evaluation of female feet and leg joint conformation at time of selection and post first parity in swine. J. Anim. Sci. 96, 3549-3557. doi:10.1093/jas/sky227

Tart, J.K., Johnson, R.K., Bundy, J.W., Ferdinand, N.N., McKnite, A.M., Wood, J.R., Miller, P.S., Rothschild, M.F., Spangler, M.L., Garrick, D.J., Kachman, S.D. \& Ciobanu, D.C., 2013. Genome-wide prediction of age at puberty and reproductive longevity in sows. Anim. Genet. 44, 387-397. doi:10.1111/age.12028.

Tholen, E., Bunter, K.L., Hermesch, S. \& Graser H.U., 1996a. The genetic foundation of fitness and reproduction traits in Australian pig populations 1. Genetic parameters for weaning to conception interval, farrowing interval, and stayability. Aust. J. Agric. Res. 47:1261-1274.

Tholen, E., Bunter, K. L., Hermesch, S. \& Graser, H.U., 1996b. The genetic foundation of fitness and reproduction traits in Australian pig populations 2. Relationships between weaning to conception interval, farrowing interval, stayability, and other common reproduction and production traits. Aust. J. Agric. Res. 47, 1275-1290.

VanRaden, P.M. \& Klaaskate. E.J.H., 1993. Genetic evaluation of length of productive life including predicted longevity of live cows. J. Dairy Sci. 76, 2758-2764. 
Veerkamp, R.F., Brotherstone, S., Engel, B. \& Meuwissen, T.H.E., 2001. Analysis of censored survival data using random regression models. Anim. Sci. 72, 1-10.

Webb, A. J., Russell, W.S. \& Sales, D.I., 1983. Genetics of leg weakness in performance-tested boars. Anim. Prod. 36, 117-130.

Yazdi, M.H., Lundeheim, N., Rydhmer, L., Ringmar-Cederberg, E. \& Johansson, K., 2000a. Survival of Swedish Landrace and Yorkshire sows in relation to osteochondrosis: A genetic study. Anim. Sci. 71, 1-9.

Yazdi, M.H., Rydhmer, L., Ringmar-Cederberg, E., Lundeheim, N. \& Johansson, K., 2000b. Genetic study of longevity in Swedish Landrace sows. Livest. Prod. Sci. 63, 255-264. 